\title{
The Inequality of Fair Play: Lottery Gambling and Social Stratification in Germany
}

\author{
Jens Beckert and Mark Lutter
}

\begin{abstract}
On the basis of a telephone survey conducted on a random sample of the German residential population, we examine the distribution effects state lotteries have on Germany's social structure. Lotteries are highly taxed economic transactions, whose proceeds make up a considerable share of public fiscal revenues. Our analysis shows that lotteries are a form of regressive taxation. Using key demographic indicators, such as age, citizenship, and levels of income and education, we demonstrate the effects of fiscal redistribution.
\end{abstract}

\section{Introduction}

Lotteries are instruments of redistribution. This is true in three ways: first, the gamblers consent to their stakes being redistributed in such a manner that a small group of players determined by chance (the winners) pockets the entire amount paid out. Most gamblers lose their stakes. For every winning combination paid out in Germany's classic Lotto game ' 6 out of 49', there are 54 combinations for which gamblers lose their stakes completely.

Second, lotteries are instruments of redistribution in the sense that only a part of total turnover is paid out to the winners. This type of redistribution does not take place between the players, but between players and the government. In the German game Lotto, approximately 48 per cent of the total stakes are paid out to the winners. Thirteen per cent are used to cover the costs of running the lottery, 39 per cent go to the government in the form of taxes or as concession levies. Therefore, lotteries are a very highly taxed economic transaction. Seen from a historical perspective, lotteries have been a significant source for financing public ventures; in fact, the government's intention to raise revenue was the main reason for organizing them (cf. Garvía, 2007a). For example, English lotteries were used to finance the first permanent English settlement in America (Findlay, 1986), and even schools like Harvard or Princeton were funded by lottery proceeds (Clotfelter and Cook, 1991). Today, the government's revenue from statelicensed gambling is approximately five billion euros per year in Germany, and Lotto alone contributes roughly two billion euros, the largest individual share.

Finally, lotteries are-at least potentiallyinstruments of redistribution in a third respect. If it were the case that different strata of the population did not participate in the lottery to the same extent, then lotteries would also be an instrument of governmental social redistribution. The actors who contribute more to government revenue from gambling because of their larger stakes would bear a higher burden. The funds raised by the government by means of lotteries can be assessed employing the same normative criteria of tax equity which are used for other sources of public revenue. This raises the question whether certain groups of the population contribute disproportionately high shares to the fiscal revenue.

In this article, we examine the distributional effects of the lottery in Germany in terms of social 
stratification. The problem of social redistribution by means of lotteries is one of the most significant subjects of social-science research on gambling (for an overview, see Miyazaki, Hansen and Sprott, 1998). Redistribution through gambling is sociologically relevant, particularly in its effects on social inequality. Many studies, most of which were carried out in the United States, provide evidence that lotteries are a form of regressive taxation. Low-income individuals spend a higher proportion of their incomes for lottery tickets than do individuals with higher incomes. This question has not yet been answered for Germany (Tolkemitt, 2002, p. 155).

With this article, we build on the international discussion about the distributional effect of lotteries by identifying which sociodemographic groups are predominantly responsible for the demand and therefore the revenue generated by the game in Germany. In doing so, we examine the income elasticity of the demand for Lotto tickets and place the results in the context of the international discussion. The results show that the amount of taxes paid varies with the level of income to a disproportionately low degree. Accordingly, regressive tax effects can also be found for the German Lotto.

In the first section of the article, we present the fiscal relevance of the German gambling market with particular reference to lotteries. In the second section, we discuss theoretical approaches to explaining the disproportionately high demand of Lotto tickets on the part of the lower social strata as well as the state of research on redistributional effects of lotteries. In the last section, we conduct an empirical analysis of the redistribution effects of the German Lotto game.

\section{The Fiscal Relevance of Gambling}

Currently, the legal, government-licensed gambling market has a gross turnover of approximately 30.5 billion euros per year, ${ }^{1}$ which corresponds to approximately 1.3 per cent of Germany's GDP. The segments with the highest turnover within this market are casinos (31\%), the Deutsche Lotto-Toto-Block (27\%) and slot machines $(18 \%){ }^{2}$ The stakes of the game ' 6 out of 49 '- the classic Saturday and Wednesday Lotto-constitute approximately two-thirds of turnover for all the games of the Deutsche Lotto-Toto-Block. In 2006, the annual turnover of this game came to just over five billion euros.

Government revenue generated by gambling currently amounts to approximately five billion euros ${ }^{3}$ and is therefore of considerable fiscal importance. This applies especially to the budgets of the Länder (the German federal states), where income from gambling makes up approximately 18 per cent of their total tax revenue. In all, approximately 1.1 per cent of total government revenue comes from gambling. Gambling revenue roughly equals revenue of the real estate transfer tax, is 20 per cent higher than inheritance tax revenue, and 50 per cent higher than revenue from alcohol-related taxes (cf. Bundesministerium der Finanzen, 2006; Deutsche Hauptstelle für Suchtfragen e.V., 2006).

Gambling revenue is raised from taxes on racing betting, on lottery tickets, and on casinos as well as from concession fees and Zweckabgaben (taxes for a particular purpose). Funds from this last type of tax flow either directly into the budget of the respective Land and are thus subject to parliamentary control, or they are allocated directly to civic groups to be spent for a particular purpose. As a rule, these funds benefit nonprofit projects, recreational sports, social services, cultural institutions such as museums and theaters, and the protection of historic buildings and monuments.

The combination of lottery taxes and concession fees make lottery tickets-at a tax rate of 39 per centhighly taxed goods compared with other consumer goods. The vast majority of consumer goods are only subjected to value-added tax at a rate of 7 per cent or 19 per cent; cigarettes are also subject to a 24.2 per cent tax of the purchase price. Only the fuel tax, which makes up approximately 66 per cent of the sale price of gasoline, exceeds the rate at which lottery tickets are taxed.

Taxation of lottery tickets is high a fortiori if one considers them a financial investment (Friedman and Savage, 1948; McCaffery, 1994). Other transactions regarded as investments are not taxed at all or at a much lower rate: for example, the real estate transfer tax is set at 3.5 per cent of the purchase price (except in Berlin); only profits gained from transactions in the financial markets are taxed, with many exemptions; and purchases of artwork are taxed at the reduced value-added tax rate.

Thus, the high taxation of lottery tickets cannot be explained by the government's sense of responsibility to fight pathological gambling by raising the price of lottery tickets. If the demand were to be reduced effectively, the structure of the game would have to be changed, for example, by offering much lower jackpots. Instead it underscores the intention of the state to raise revenue.

In taxation theory, the quality of a tax is assessed according to two basic principles 
(Murphy and Nagel, 2002): the ability-to-pay principle and the benefit principle. The ability-to-pay principle states that the burden of a tax is to be distributed as fairly as possible according to the economic situation of those paying the tax. As a rule, a person's economic situation is measured via his/her income as an indicator for wealth. The level of a tax burden should be at least proportional to the level of income, but would ideally increase progressively. In other words, the tax burden should grow disproportionately with increasing economic ability. Surveys show that the principle of progressive taxation meets with broad acceptance on the part of the general population (Liebig and Mau, 2005).

The benefit principle demands a just use of the revenue, oriented towards the taxpayers' preferences or their consumption patterns. According to this principle, those who pay the tax have to agree with the way in which the funds are spent, or they must be able to benefit in some way from their use. However, since no specific expenditures for the lottery players correspond to the lottery tax revenue-such expenditures are already taken into account because the turnover of the game covers the costs of conducting the lottery-the tax cannot be legitimated by the benefit principle. This is true at least for the government revenue from gambling that accrues to the general budget. For this revenue, the ability-to-pay principle should be applied. That is, this tax would be considered fair if the revenue were at least proportional to the lottery players' incomes or if the revenue were even to display progression in such a manner that higher income groups were to contribute to a disproportionally high degree to this type of tax revenue. If this is not the case, then one would speak of a distributional effect of the state lottery that did not correspond to this principle of taxation. The taxation would be regressive.

\section{State of Research}

\section{Theoretical Derivations of Socially Stratified Demand Behaviour}

Theories explaining the demand for lottery tickets frequently make the relationship between demand structure and social stratification a subject of discussion, whereby researchers almost uniformly assume that playing the lottery has a special fascination for the lower social strata. In this vein, approaches based on cognitive psychology explain participation in gambling with the players' limited cognitive abilities, meaning that these people tend to systematically overestimate the very low chances of winning in lotteries (Kahneman and Tversky, 1979; Rogers, 1998; Rogers and Webley, 2001). It is assumed that misjudgment of the statistical rules of games of chance generally corresponds with a lower educational level or social status on the part of the players. Indeed, empirical studies show a correlation between lower education levels and an overly positive perception of winning the jackpot (Beckert and Lutter, 2007, p. 248; Nibert, 2006, p. 324).

According to functionalist sociological theories of tension management, the demand for lottery tickets also relates to social stratification. Participation in gambling is explained as an attempt to escape from structural tensions inherent in modern societies (Bloch, 1951; Devereux, 1980; Frey, 1984). The anomie variant of this theory postulates that individuals who perceive status inconsistencies play the lottery to a greater degree because they link winning the lottery with the hope of being catapulted upwards on the social ladder. According to this theory, greater participation in gambling is to be expected of the lower middle classes, since they, more than other strata, find themselves in a tension-laden social hierarchy between high upwardly directed aspirations of social mobility and strong restrictions in the opportunities for social climbing (Tec, 1964; Frey, 1984). This assumption, too, is confirmed empirically (Downes et al., 1976; Smith, Preston and Humphries, 1976; King, 1985; Beckert and Lutter, 2007). In addition, people also tend to purchase more lottery tickets when they are in desperate financial circumstances, in the hope that the jackpot will radically change their situations. Since the lower social strata have a greater probability of finding themselves in such life situations, this is an additional strata-related factor in the demand structure (Blalock, Just and Simon 2007).

It is also assumed that the lower strata's stronger fascination with lotteries can be explained by the fact that the chances of winning are completely equal (McCaffery, 1994, p. 88). It is not personal achievement, talent, creativity, or social and cultural capital that determine success in gambling, but chance alone. This distribution of chance differs from all other distributional situations in modern societies. Members of the lower social strata find the egalitarian distribution of chance more attractive because their chances of being a winner are relatively better than in meritocratic or ascriptive distributional situations.

Finally, the greater attractiveness of gambling for the lower social strata can be explained using theories of consumption. More recent sociological theories of consumption explain the demand for consumer 
goods in functionally saturated markets with fantasies evoked by the purchase of consumer goods (Campbell, 1987). Consumer goods induce fantasies about realizing material dreams and the enhanced social recognition associated with them. This holds true for lottery tickets to a particular degree. Two-thirds of all lottery gamblers imagine what they would do with their potential winnings (Beckert and Lutter, 2007, p. 266). While these lottery-induced fantasy worlds are 'cheap', lower social strata are excluded from most other 'evocative consumer goods'. This includes expensive status goods, such as exquisite clothing, wines, or luxurious cars (cf. Cohen, 2001, p. 730ff.). Because of their relative exclusion from other opportunities for consumption, lower social strata are drawn to lottery tickets to a greater degree than members of higher social strata (Blalock, Just and Simon, 2007).

Most research on the distributional effects of lotteries points towards regressive effects. The theoretical approaches cited can indeed plausibly explain this selection of demand. To what extent can the regressive distributional effects of lotteries established in the literature be corroborated for Germany as well? In order to answer this question, we will empirically test the hypothesis that Lotto tickets represent a regressive form of taxation because low-income individuals purchase them to a disproportionally high degree relative to their incomes.

\section{Empirical Results Regarding the Effect of Lotteries on Social Stratification}

The question about the distributional effects of lotteries has been examined in particular for the United States. Many of these studies conclude that lotteries are a form of regressive taxation and that their distributional effects are thus uneven with regard to social stratification. This finding appears to be a relatively uniform result whose robustness is supported by the use of entirely different types of data and methods. Some studies analyse only macrolevel aggregate data and study the relationship between turnover per capita and the income levels of certain geographical areas (Clotfelter, 1979; Vasche, 1985; Mikesell, 1989; Jackson, 1994; Hansen, 1995). Other studies examine the tax incidence of lotteries by means of microlevel data, mostly by employing representative population survey data or data from surveys of lottery winners (Spiro, 1974; Brinner and Clotfelter, 1975; Suits, 1977a; Livernois, 1987; McConkey and Warren, 1987; Borg and Mason, 1988; Vaillancourt and Grignon, 1988; Clotfelter and Cook, 1991; Kitchen and Powells, 1991). Further studies combine micro- and macrolevel data, for example, Clotfelter and Cook (1987), Koza (1982), or Heavey (1978).

The methods of calculating regressivity are also diverse. Some studies merely show simple associations, such as the relationship between lottery expenditures, measured as its proportion of income, and available net income (Brinner and Clotfelter, 1975). A widely used approach is to apply the Suits index, a measure of tax concentration that summarizes the distribution of income and tax burden in a manner analogous to Gini's ratio (cf. Suits, 1977b). Only a few studies specify multivariate models, which model the elasticity of income with the level of the taxes paid (Borg and Mason, 1988).

The studies differ not only in their methods, but also in their conclusions about the size of regressive effects. ${ }^{4}$ Price and Novak (1999) provide evidence that the taxation of lottery tickets in Texas is more regressive than the value-added tax. Using macrolevel, time-series data, Hansen, Miyazaki and Sprott (2000) provide evidence for five US states that there has been a stronger regressive incidence recently than is shown in earlier data sources for the same states. In addition, there appear to be national differences in the power of regressive effects. Studies in Canada show that Canadian lotteries are consistently less regressive than US lotteries (cf. Livernois, 1987; Vaillancourt and Grignon, 1988; Kitchen and Powells, 1991). The findings for various games of chance differ as well. Daily lotteries or scratch games are more regressive, compared to traditional lotteries (cf. Mikesell, 1989; Clotfelter and Cook, 1991; Price and Novak, 1999), which indicates a different socially stratified demand structure for different lotteries as well as for different countries.

In general, these findings correspond to the criticism frequently levelled against lotteries that they especially burden the socially disadvantaged strata (Braidfoot, 1985; Karcher, 1989, 1992; Clotfelter and Cook, 1991; Reith, 1999; Clotfelter, 2000; Nibert, 2000, 2006; Cosgrave and Klassen, 2001; Husz, 2002). To Reith (1999, p. 100), for example, the lottery is a government-organized exploitation of the dreams of the socially disadvantaged strata, whose members see the lottery as their only possible escape from their position in the capitalist system. In fact, studies demonstrate that the demand for lottery tickets correlates not only with relatively low levels of income but also generally with lower socioeconomic status, meaning lower educational levels, employment status, and ethnic minorities (cf. Clotfelter and Cook, 1991; Brown, Kaldenberg and Browne, 1992). 


\section{Data and Method}

\section{Sample}

In order to test our hypothesis that Lotto tickets represent a regressive form of taxation, we employ primary data from a CATI survey of the general population on the demand structure of Lotto gamblers in Germany. This study was conducted by a socialscience survey institute (SUZ, Duisburg, Germany) on behalf of the Max Planck Institute for the Study of Societies in Cologne. The field work was carried out in the spring of 2006. Prior to the study, we developed a survey instrument that was quality-tested in several steps: by holding qualitative group discussions with a group of Lotto gamblers, by obtaining expert evaluations from specialists in survey research (ZUMA in Mannheim, Germany, among others), and by conducting two pretests in the field. In the defined population of the survey, we included all individuals over 18 years of age who were residents of Germany and lived in households with a landline telephone. We use a random digit dialing (RDD) sampling procedure, modified for the particular German structure of landline telephone numbers (cf. Gabler and Häder 1997), to generate a simple random sample of the defined population. Target persons within the household were selected randomly by the last birthday method and were then asked if they had played Lotto at least once within the past year. These respondents are defined as Lotto players. We then employed an approach with a disproportionally stratified sample in which we selected Lotto players overrepresented by a factor of approximately 1.66 in relation to their absolute frequency in the population. For all analyses referring to the total population, we use weighting factors to compensate for the disproportionality due to the sampling method. Prior to the main survey, we estimated the ratio of Lotto players to non-players in the population by a larger pretest with a sample size of $n=200$, whereby we also employed a standardized cognitive pretest for the questionnaire following the method developed by Deutschmann, Faulbaum and Kleudgen (2003). In total, 1508 interviews were carried out for the main sample: 1002 with Lotto gamblers and 506 interviews with non-gamblers. The response rate of the sample is 25.7 per cent. According to German census data, our sample is demographically representative with regard to gender, but slightly overrepresented by middle values of age, income, and education. Survey estimates indicate that 40 per cent (Std. Error $=$ 1.26) of the German adult residential population play the lottery at least once a year, 22.3 per cent
$($ Std. Error $=1.07)$ play regularly at least once a month, and 17 per cent (Std. Error $=0.96)$ play at least once a week. Monthly players spend an average of 16.9 euros for Lotto tickets (Std. Error $=0.8$ ), while weekly players spend an average of 30.1 euros (Std. Error $=1.63$ ) per month.

\section{Construction of the Variable 'Contribution to Tax Revenue'}

A central criterion of the following incidence analysis is the level of taxes paid by the individual resulting from his/her demand for Lotto tickets. This is a constant percentage of the amount paid for tickets within a particular period of time. The sum of expenditures is therefore a central variable in our analysis. As a rule, researchers conducing surveys ask about certain figures, such as income, consumption expenses, etc., retrospectively for a particular given period of timeusually 1 month. For various reasons, however, the adequate measuring of gambling expenditures is no trivial endeavor and cannot employ the usual survey methods (Blaszczynski, Dumlao and Lange, 1997; Wood and Williams, 2007). In this vein, a question posed retrospectively about the level of a player's monthly Lotto stake can be biased, since it is dependent on the Lotto ticket's period of validitywhich may be up to 12 weeks in the German game. Therefore, it is appropriate not only to ask how much the average monthly stake was, but also to take into account the average period of validity of the game played. In addition, individuals surveyed may not be sure whether they are being asked about the net stake minus any winnings or about the gross amount.

Aware of these issues, we asked the target group defined as Lotto players how often they had participated in the Saturday or Wednesday games within the past year. We then derived the number of days on which the participants gambled per year from the three categories for responses provided-'regularly at least once a week', 'at least once a month', and 'only a few times a year' - by assigning the value of 52 to the first category, the value of 18 to the second, and the value of 8 for the third. At the same time, we asked the players about the period of validity of the tickets they usually purchased, and about the gross amount they paid on average each time they played Lotto. We then calculated the average annual Lotto expenditures (EXP) via the formula $\operatorname{EXP}=(p / q) r$, where $p$ is the player's average amount of expenditures per participation in the game, $q$ is the average period of validity for the ticket, and $r$ is the estimated number of days a player participated in the game within the past year. 
Then, the quotient $p / q$ constitutes an estimator of the player's average stake per participation in a drawing of the game. This term multiplied with $r$ yields to the annual average total stake. ${ }^{5}$ By dividing this variable by 12, we derived the monthly average Lotto expenditures of the players.

A further central variable of the following analysis is income, and for this reason, we describe how this variable, too, is constituted. Generally in surveys, the measuring of income is not only associated with the problem of systematically biased responses, but also with generally high and partly systematic refusal rates (Groves et al., 2002). Our questionnaire surveyed income in two stages. In the first step, an open question was posed about the net household income available per month, meaning all income minus fixed costs, such as taxes, rent, etc. Single-person households were asked directly about their personal monthly net income. If the individual refused to state his/her income in response to this first open question, the question was asked a second time, with special reference to anonymity, but this time with predefined income groups. In the next step, the two stages were merged using the means of the income groups as the best possible approximation of the actual value. ${ }^{6}$ In order to take into account the differences in needs of different household structures, the per capita net household equivalence income then was calculated from the composite income variable, according to the OECD's modified equivalence scale (cf. Hagenaars, de Vos and Zaidi, 1994).

\section{Findings}

In the following, we examine how tax revenue is distributed according to the economic situation of the taxpayers. An initial descriptive approximation from our survey data is shown by the average monthly gambling expenditures in absolute terms and relative to income for the five income quintiles of the available monthly net income shown in part A of Table 1. A diametrically opposed pattern of the two variables becomes apparent. While absolute expenditures increase monotonically, expenditures measured in relation to income decrease with increasing income. Higher income gamblers therefore contribute less to tax revenue relative to their ability to pay.

Incidence measures that rely on mean values alone do not do justice to one important point (cf. Clotfelter and Cook, 1987, p. 537ff.): stakes are not distributed equally among all gamblers. Rather, a small percentage of gamblers accounts for a large part of turnover. According to our survey, the top quarter of gamblers with the highest expenditures accounts for approximately 70 per cent of total turnover. Half of the turnover is borne by a minority of just 12.6 per cent of the gamblers.

This means that we must take into account the concentration of revenue when analyzing tax incidence. Part B of Table 1 displays the mean expenditures, both absolute and relative to income, only for those gamblers who are among the top 25 per cent spending the most on gambling and thereby contributing the largest part of total tax revenue. The table shows marked differences to part A of Table 1. First, the means of the absolute expenditures in all income quintiles are higher by more than a factor of two. In addition, absolute expenditures do not increase with income, but remain on high level within all income classes. According to the relative incidence of gambling, the share-of-income expenditures of the frequent gamblers are two to three times higher than that of the entire group. Moreover, the variation within income quintiles has a range of more than 10 per cent. The mean stake in the lowest quintile accounts for almost 12 per cent of the gamblers' available net income, but only roughly two per cent in the highest

Table 1 Mean and top quarter mean monthly expenditures for Lotto; absolute and as percentage of income by income quintiles

\begin{tabular}{lcccc}
$\begin{array}{l}\text { Income quintiles } \\
\text { (per cent) }\end{array}$ & $\begin{array}{c}\text { Mean expenditures } \\
\text { Relative } \\
\text { (euro) }\end{array}$ & $\begin{array}{c}\text { A } \\
\text { (per cent of income) }\end{array}$ & $\begin{array}{c}\text { Top quarter mean expenditures } \\
\text { Absolute } \\
\text { (euro) }\end{array}$ & $\begin{array}{c}\text { Relative } \\
\text { (per cent of income) }\end{array}$ \\
\hline $0-20$ & 12.8 & 3.1 & 48.0 & 11.7 \\
$20-40$ & 15.9 & 2.0 & 42.4 & 5.3 \\
$40-60$ & 18.3 & 1.8 & 51.7 & 5.1 \\
$60-80$ & 17.0 & 1.2 & 44.1 & 3.1 \\
$80-100$ & 22.0 & 0.9 & 52.3 & 2.4 \\
\hline
\end{tabular}


quintile. Therefore, the regressive pattern of the lottery tax becomes very clear for the players who contribute the most.

Another option for describing deviations from the ability-to-pay principle is the Suits index (1977b), a measure of concentration that summarizes the degree of regressivity based on the deviation of the area below a Lorenz curve function from the area of its diagonal. The Lorenz curve is the two-dimensional representation of the cumulative relative proportion of the net income in relation to the total income for a population of Lotto players and the cumulative proportion of the expenditures for Lotto tickets-as an estimate of the taxes paid —of the total stake. The measure is defined, in analogy to Gini's ratio, as the relationship $S=1-L / K$ whereby $-1 \leq S \leq 1$, while $L$ indicates the area below the Lorenz curve obtained in this way, and $K$ indicates the area below the diagonal which represents perfect proportionality regarding taxation. In the case of extreme progressivity, that is, if the entire tax burden is borne by the highest income segment, the value is +1 , whereas the value of 0 signifies a proportional tax, and values less than 0 indicate a regressive tax distribution. According to our calculations, the index has a value of -0.23 , which indicates a distinctly regressive distribution. Figure 1 is a graphic representation of this correlation based on the deviation of the Lorenz curve from its diagonal. The curve lies above the diagonal which demonstrates the regressivity of the tax.

The index offers some easy-to-recognize advantages, which may be one reason why a large number of the above-mentioned studies rely exclusively on it. The coefficient can be interpreted clearly and permits one to draw conclusions intuitively via the graphic representation. The measure is also suitable as a

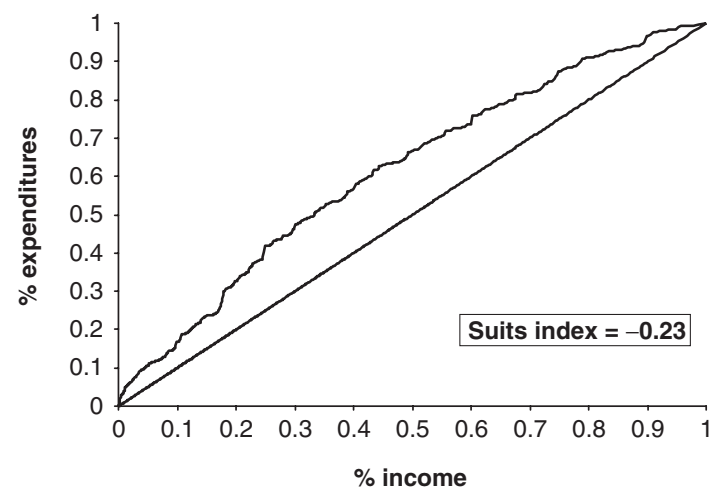

Figure 1 Lorenz curve of tax concentration by income; Suits index reference value for comparing the findings of other studies or the regressivity of other games of chance with one another (cf. Suits, 1977b).

Nonetheless, this measure has some serious disadvantages (concerning criticism, see Calmus, 1981). Like Gini's ratio, the Suits index depends on how the original data are scaled. Therefore, statements that are based on a comparison of this measure must be interpreted with caution if the measures are calculated on the basis of values that are scaled in different ways. That this is true for most of the studies mentioned above is revealed only by the variety of data used in them. A further disadvantage is that the distribution of only two variables together-expenditure and income-is shown. This excludes the possibility of controlling for possible other effects. In fact, Hansen, Miyazaki and Sprott (2000, p. 195f.) as well as Borg and Mason (1988, p. 77) report substantial differences between their findings based on bivariate incidence analyses, and multivariate models that control for other variables. Therefore, research that relies only on a bivariate examination of regressivity must be regarded with caution.

A multivariate model offers a substantially more differentiated possibility for analyzing regressivity. A measure of regressivity can be obtained by estimating the income elasticity of the demand for lottery tickets. In general, elasticities are obtained as regression coefficients of a double log-linear model specification (Gujarati, 2003, p. 175f.). In order to determine the income elasticity, we will estimate the logarithm of lottery expenditures-a proxy for the taxes paid-as a linear combination of the logged net income and further sociodemographic covariates. The regression coefficient of the logged income then becomes a point estimator of income elasticity. If the coefficient is less than one, the tax can be considered regressive. In this case, the taxes paid increase disproportionally with income. If the coefficient equals one, the tax burden increases proportionally with income; but if the value is greater than one, the taxes paid are progressive in relation to income.

In all, we estimate three models: using a logit model, we first determine the sociodemographic determinants of the binary decision to play Lotto once or more within a year. This model offers insight into the social background of the players. Then we estimate the average amount spent on lottery tickets as a function of sociodemographic variables. In doing so, we employ two log-linear model specifications. In the first, we include the absolute amount, and in the second, we include the logged amount of expenditures as the dependent variable. 
Table 2 Regression models of the sociostructural incidence of Lotto ticket demand

\begin{tabular}{|c|c|c|c|}
\hline & $\begin{array}{c}\text { (1) } \\
\text { Participation } \\
(1=\text { Lotto gamblers; } \\
0=\text { non-gamblers })\end{array}$ & $\begin{array}{c}\text { (2) } \\
\text { Monthly } \\
\text { Expenditures } \\
\text { (in euros) }\end{array}$ & $\begin{array}{c}\text { (3) } \\
\text { Monthly } \\
\text { Expenditures } \\
\text { (in euros, log) }\end{array}$ \\
\hline Income (in euros, log) & $1.205(1.37)$ & $3.537(2.10)^{* *}$ & $0.280(3.95)^{* * *}$ \\
\hline Gender $(1=$ male $)$ & $1.154(1.01)$ & $1.686(0.99)$ & $0.062(0.86)$ \\
\hline Age (in years) & $1.087(3.24)^{* * *}$ & $-0.017(0.25)$ & $-0.003(1.19)$ \\
\hline Age (squared) & $0.999(2.54)^{* *}$ & & \\
\hline Education $(1=$ low; $5=$ high $)$ & $0.800(3.39)^{*}$ & $-1.719(2.25)^{* *}$ & $-0.094(2.94)^{* * *}$ \\
\hline Employment $(1=$ full-time; $0=$ other $)$ & $1.575(2.79)^{* * *}$ & $-3.427(1.79)^{*}$ & $-0.186(2.32)^{* *}$ \\
\hline Partnership $(1=$ living with Partner; $0=$ other $)$ & $1.503(2.84)^{*}$ & $0.285(0.16)$ & $0.094(1.26)$ \\
\hline $\begin{array}{l}\text { Urban location } \\
\qquad(1=\text { population }>150.000 ; 0=\text { other })\end{array}$ & $0.769(1.77)^{*}$ & $-2.829(1.53)$ & $-0.029(0.38)$ \\
\hline Citizenship $(1=$ German; $0=$ other $)$ & $0.575(1.16)$ & $-10.637(1.81)^{*}$ & $-0.307(1.24)$ \\
\hline Lotto participation (times per year, log) & & $12.678(12.48)^{* * *}$ & $0.696(16.31)^{* * *}$ \\
\hline Constant & & $-28.163(2.26)^{* *}$ & $-1.104(2.11)^{* *}$ \\
\hline $\mathrm{N}$ & 1199 & 705 & 705 \\
\hline McFadden & 0.05 & & \\
\hline LR $\chi^{2}$ & 66.10 & & \\
\hline Adj. R-squared & & 0.23 & 0.33 \\
\hline
\end{tabular}

Significance: ${ }^{*} P<0.1 ;{ }^{* *} P<0.05 ;{ }^{* * *} P<0.01$ (two-sided test); in parantheses: $z$-statistics.

We use the following sociodemographic variables as covariates: gender (with 'women' as the reference category), age (in years), educational level (five levels, with a university degree as the highest category), partnership (1 signifies 'living together with a partner', 0 signifies 'other'), urban location (1 signifies 'regions with populations of more than 150000 ', 0 signifies 'other'), and citizenship (1 signifies 'German citizenship', 0 signifies 'other'). Additionally, we squared the age variable in the model because some findings from American studies point to a higher probability of lottery-ticket demand among middle-aged people (Clotfelter and Cook, 1991, p. 97; Scott and Garen, 1994, p. 132). ${ }^{7}$ Since gambling expenditures vary strongly with participation frequency, we also control for the estimated incidences of participation per year in the models estimating the amount of expenditures.

Table 2 documents the results of the multivariate model estimations. Each of the three models constitutes a different specification of the functional form, which is why the coefficients in the three columns are to be interpreted differently. All the coefficients represent the unstandardized solution of the model estimation. The first column shows the odds ratios (cf. Long, 1997, p. 79f.) of the binary logit model on the odds of having played Lotto at least once within a year. The two other columns show the coefficients of the differently specified OLS regressions, which all describe the influence of socioeconomic variables on the amount of expenditures for the group of Lotto players. ${ }^{8}$ In the second column, we find the results of the OLS regression for the absolute amount of lottery expenditures, and the third column reports the results of the double log-linear specification. While the regression coefficient of the logged income can now be interpreted as an estimator of elasticity in measuring the degree of regressivity, each of the other coefficients in that column describes the relative change in the amount of expenditure when the covariates increase in absolute terms.

Before we discuss income, we would like to take up the influence of the sociodemographic covariates. Education proves to be one of the most important determinants both for participation in the lottery and for the amount of expenditures: with each additional value on the five-level education scale, the odds of participating decrease by a factor of 0.8 , that is, by an average of 20 per cent (see the respective coefficient in model 1). Within the group of Lotto players, the amount of expenditures drops by roughly 10 per cent with each higher level of education (see model 3 ). Therefore, the demand for lottery tickets appears to be, first and foremost, a question of education, since the group of Lotto players, which is already overrepresented by lower levels of education, also displays distinctly higher expenditures within these levels.

Nonetheless, one can by no means speak of a phenomenon that only affects socially disadvantaged 
strata. If nothing else, the high annual prevalence of Lotto participation-40 per cent of the adult population-contradicts this notion. But it also becomes apparent that the primary Lotto gamblers are not, for example, people in precarious employment positions or the unemployed. We find full-time employees among the Lotto gamblers distinctly more frequently. That is shown by the coefficient of employment in the model estimating the odds of participation. Nonetheless, this finding applies only to the decision whether or not to gamble. Once the decision to participate has been made, it is interesting that the employment variable has a significantly negative effect on the level of expenditures, as is shown by the now changed algebraic sign for this coefficient in models 2 and 3. In this case, it becomes apparent that Lotto players who work fewer hours spend approximately 19 per cent more on stakes than do full-time employees (see model 3).

A number of more statistically significant differences can be observed for the other variables. In the first model, age proves to be a significant factor for participation in the game. The squared specification of this term implies an inverted U-shaped curve representing the relation between age and the odds of playing the lottery. For this variable, the maximum predicted probability of approximately half is calculated for the age of 63 , holding the effects of all other variables constant at their sample mean. This means that practically every other 'sociostructurally average' resident of Germany between 60 years and 65 years of age plays Lotto.

Further significant determinants of the odds of gambling include the variables 'partnership' and 'urban location'. It becomes apparent here that Lotto players tend to live with a partner in a non-urban region with communities of less than 150000 . Yet, regarding the amount of expenditures, none of these effects display sufficient statistical significance, and for this reason, the variation in expenditures cannot be explained substantially by the variables age, partnership, or urban location. In addition, there are no significant gender differences regarding both the odds of participating and the level of expenditures. Findings from American studies show that members of ethnic minorities participate more in lottery gambling (cf. Clotfelter and Cook, 1991, p. 98; Scott and Garen, 1994, p. 132). Our data, too, show similar results for the variable 'citizenship', used as an approximation for belonging to an ethnic minority. While this variable shows no difference in the decision to play, the second model does show an effect. On average, non-Germans spend 10 euros more on lottery tickets than do individuals with German citizenship. However, this effect has only limited statistical significance because of the interplay between a very small number of cases and the existence of outliers for this group. Accordingly, the effect loses statistical precision in the third model because of the smoothing effect of the logarithm on the left-hand side of the equation and now lies outside of conventional significance levels of at most 10 per cent.

Still, what is the effect of income as the central variable in our research? The first column shows that the level of income is statistically irrelevant for the decision to participate in the game. On average, Lotto players have neither higher nor lower incomes than non-gamblers. Once the decision to participate has been made, however, income becomes a significant determinant of the level of the stakes. As the positive correlation in the second model shows, the amount of money spent on the game rises significantly with increasing income. This finding is also supported by other studies (Kitchen and Powells, 1991, p. 1847f.) but is not an argument against the hypothesis of regressivity, since expenditures on gambling measured as a share of income are decisive for assessing regressivity, not the absolute level of expenditures. This relationship can be explored adequately only by means of a log-linear model specification, as shown in the third column of Table 2. With 0.28 and a statistical error tolerance of \pm 0.14 at the 95 per cent level, the coefficient presented there is clearly less than one, thereby indicating regressive income elasticity. The value implies that an increase in income of 1 per cent corresponds with an increase in Lotto expenditures, on average, of 0.28 per cent. Therefore, the taxes paid increase to a disproportionately low degree with income, which supports the hypothesis of regressivity.

Comparing these findings with earlier studies shown in Table 3, we find that the degree of regressivity for the German Lotto ranks in the middle of the findings from the United States, Canada, and Spain. Spain, the only other European country for which information is available, features slightly stronger regressivity compared with Germany (cf. Garvía, 2007b; Guillén, Garvía and Santana, 2008). The consistently strongest regressive distributional effects are found in the United States, while Canada displays the least regressivity of the countries studied.

\section{Conclusion}

On the basis of the data we collected, we were able to show that the government-operated lottery Lotto represents a form of regressive taxation that violates 
Table 3 Summary of previous findings regarding the regressivity of the lottery tax

\begin{tabular}{rlrlrl} 
No. & \multicolumn{1}{c}{ Study } & Year & \multicolumn{1}{c}{ Country } & S & $\boldsymbol{\eta}$ \\
\hline 1 & Spiro (1974) & 1972 & USA (PA) & -0.20 & 0.21 \\
2 & Suits (1977) & 1973 & USA & -0.31 & \\
3 & Brinner and Clotfelter (1975) & 1973 & USA (CT, MA, PA) & -0.44 & \\
4 & Koza (1982) & $1971-76$ & USA (MI, NJ, IL, NY) & -0.38 & \\
5 & Clotfelter (1979) & 1978 & USA (MD) & -0.33 & \\
6 & Vaillancourt and Grignon (1988) & 1982 & Canada & -0.18 & 0.69 \\
7 & Livernois (1987) & 1983 & Canada (Edmonton, Alberta) & -0.10 & 0.72 \\
8 & Jackson (1994) & 1983 & USA (MA) & -0.36 & 2.44 \\
9 & Clotfelter and Cook (1987) & 1984 & USA (MD) & & 0.25 \\
10 & Borg and Mason (1988) & $1984-86$ & USA (IL) & -0.18 & 0.77 \\
11 & Kitchen and Powells (1991) & 1986 & Canada (6 regions) & & 1.26 \\
12 & Mikesell (1989) & $1985-87$ & USA(IL) & -0.21 & 0.49 \\
13 & Jackson (1994) & 1990 & USA (MA) & -0.23 & 0.18 \\
14 & Price and Novak (1999) & 1994 & USA (TX) & -0.23 & 0.28 \\
15 & Garvía (2007b) & 2006 & Spain & Germany & \\
16 & Beckert and Lutter (this study) & 2006 & Gen & \\
\hline
\end{tabular}

Note: $S$ is the Suits index (Suits 1977 a); $\eta$ is an estimator of elasticity; (1) Data set: survey of lottery winners; combined from various lotteries; alculation of $S$ taken from Suits (1977b); $\eta$ stems from a bivariate model; (2) Data set: national household survey; combined from various lotteries; (3) Data set: survey; passive lottery; S corresponds to the mean of three individual values; as quoted in Clotfelter and Cook (1991); (4) Data set: regional aggregate data, combined with survey data; lottery; S corresponds to the mean of four individual values; (5) Data set: regional aggregate data and turnover figures; $S$ corresponds to the mean of two individual values; (6) Data set: national household survey, various lotteries combined; (7) Data set: survey in Edmonton, Canada, various lotteries combined; (8) Data set: regional aggregate data combined with survey data, various lotteries combined; (9) Data set: survey data; lotto; (10) Data set: survey of lottery winners; various lotteries combined; $\eta$ stems from a multivariate model; (11) Data set: national householdsurvey; various lotteries combined; $S$ and $\eta$ correspond to the mean of six individual values each; (12) Data set: regional aggregate data and turnover figures; various lotteries combined; $\eta$ does not differ significantly from 1; (13) Data set: regional aggregate data and turnover figures; various lotteries combined; (14) Data set: regional aggregate data and turnover figures; lotto; (15) Data set: survey data; various lotteries

the ability-to-pay principle laid down in taxation theory as a normative criterion for assessing a tax. Lotto players with low incomes contribute to statelottery revenue to a significantly higher degree than players from higher income groups. At the same time, we were able to show that the demand for Lotto tickets is determined in a particular way: in terms of social stratification, it is predominantly the lower middle classes with lower educational levels but mostly average absolute incomes who play the most. This finding corroborates the results of international studies on this topic, most of which were carried out in the AngloSaxon countries. In addition, we could demonstrate correlations to the gamblers' employment status, age, and immigrant background.

Although the total effect of the tax system is decisive for its normative assessment, and furthermore, the tax that is being collected through lotteries stems from a voluntary activity, government revenue from lotteries, however, does appear problematic, since such regressive components of the taxation system are usually ignored in debates about taxation.
What conclusions can we draw from these results for lottery policy? The literature on this topic includes suggestions for compensating the regressive taxation effects by expanding the game (cf. Oster, 2004; Borg and Stranahan, 2005). For example, advertising for lottery products could be increased in order to reach additional strata of the population. In light of political debates about combating problem gambling, however, it appears unthinkable to expand the demand structure, because people who would otherwise not participate in the game would be encouraged to do so.

An alternative to this proposal focuses on the expenditure of the revenues that the government raises through the lotteries. If it is true that the lottery taxes are paid to a disproportionately high degree by lower income individuals, then this revenue should be used for purposes that would benefit precisely such people to a disproportionately high degree.

Finally, current proposals under discussion in the political and legal realms seek to break up the government monopoly on lotteries and liberalize the market. Yet it cannot be expected that this would 
reduce the regressive effects of lotteries. Private profits in the top income quintile would accrue, bringing about direct social redistribution.

\section{Notes}

1. Figures apply for the year 2005 (cf. SES Research, quoted in Financial Times Deutschland, July 30, 2006).

2. The Deutsche Lotto-Toto-Block is the umbrella organization of the 16 lottery companies of the German federal states. Its net market share is much higher, because the individual segments of the gambling market operate with different payout quotas. While slot machines, gambling casinos, or horse race betting pay out 70 per cent to 97 per cent of the stakes as winnings, the mean payout of the games of the Lottoblock is 48 per cent. If one takes this into account when estimating the net market volume of the individual segments of the gambling market, then the Deutsche LottoToto-Block is the largest vendor on the German gambling market (Tolkemitt, 2002, p. 30).

3. This figure is based on a projection of current turnover on the basis of the findings in Meyer (2006, p. 121f.), who estimates the tax revenue from gambling to be 4.2 billion euros in 2004. The approximately 700 million euros of tax revenue from stakes in slot machines in 2004 must be added to this figure. Slot machine gambling is considered to be a de facto, but not a de jure game of chance.

4. A small number of studies establish proportional or even progressive tax effects. Mikesell (1989), for example, employed aggregate data for the state of Illinois and determined a tax burden from lottery stakes that varies proportionally with income. Jackson (1994) even states, in a 1983 examination of the Massachusetts lottery, that distributions of lottery stakes are progressive to income. Using 1990 data to replicate the study, the same author now reports a reversal of the earlier findings and a distinctly regressive relationship between income and stakes.

5. The estimate of the stake obtained in this manner proves to be valid, as a comparison with official figures for annual turnover of the lottery companies shows. The amount projected from the figures of the sample amounts to an annual stake of 4.9 billion euros, while the actual total stakes of the lottery companies amount to approximately five billion euros for the year 2005. In other words, the value obtained from the sample underestimates actual turnover only in a negligible way.

6. This two-stage procedure reduced the nonresponse rate of income from 39 per cent to 18 per cent.

7. The specification was carried out only for estimating participation. We did not use the squared term for the amount of expenditure, since prior analyses revealed it as insignificant. In addition, the model fit-measured by using the adjusted $R$-squared-worsened slightly.

8. Some econometric studies model the decision to participate and the amount of expenditures simultaneously, employing a Tobit model, or in two steps by means of a Heckman correction (see, for example, Sawkins and Dickie, 2002; Scott and Garen, 1994; see Tobin, 1958 and Heckman, 1979 regarding the methodology in general). In our approach, we are interested in estimating the structure of each process influence individually, which is why we estimate-independent of one another-the decision to participate by means of a logit model, on the one hand, and the amount of expenditures by means of OLS regression for the group of Lotto gamblers, on the other hand. Regarding the amount of expenditures, we are interested in estimating effects only for the group of Lotto gamblers, which makes the Heckman correction unnecessary (see Winship and Mare, 1992). This way of proceeding corresponds to that of Livernois (1987), as well as Stranahan and Borg (1998).

\section{Acknowledgements}

Previous versions of this article were presented at the 103rd Meeting of the American Sociological Association, Boston, MA and at the Culture and Social Analysis Workshop, Department of Sociology, Harvard University. The authors would like to thank Fatih Dilekci for his assistance with data collection in the second section of the empirical analysis. We thank Christian Bergs, Steffen Ganghoff, Roberto Garvía, Lothar Krempel, and Jörg Rössel for their helpful comments. Research for this article was supported by the German Research Foundation (DFG) within the 
project 'Demand Behavior and Distributional Effects of the Lottery'.

\section{References}

Beckert, J. and Lutter, M. (2007). Wer spielt, hat schon verloren? Zur Erklärung des Nachfrageverhaltens auf dem Lottomarkt [The player always loses? Toward an explanation of demand behaviour in lottery markets]. Kölner Zeitschrift für Soziologie und Sozialpsychologie [Cologne Journal of Sociology and Social Psychology], 59, 240-270.

Blalock, G., Just, D. R. and Simon, D. H. (2007). Hitting the jackpot or hitting the skids: entertainment, poverty, and the demand for state lotteries. American Journal of Economics and Sociology, 66, 545-570.

Blaszczynski, A., Dumlao, V. and Lange, M. (1997). How much do you spend on gambling? Ambiguities in survey questionnaire items. Journal of Gambling Studies, 13, 237-252.

Bloch, H. A. (1951). The sociology of gambling. The American Journal of Sociology, 57, 215-221.

Borg, M. O. and Mason, P. M. (1988). The budgetary incidence of a lottery to support education. National Tax Journal, 41, 75-85.

Borg, M. O. and Stranahan, H. A. (2005). Does lottery advertising exploit disadvantaged and vulnerable markets? Business Ethics Quarterly, 15, 23-35.

Braidfoot, L. (1985). Gambling. A Deadly Game. Nashville, Tennessee: Broadman Press.

Brinner, R. E. and Clotfelter, C. T. (1975). An economic appraisal of state lotteries. National Tax Journal, 28, 395-404.

Brown, D. J., Kaldenberg, D. O. and Browne, B. A. (1992). Socioeconomic-status and playing the lotteries. Sociology and Social Research, 76, 161-167.

Bundesministerium der Finanzen [German Federal Ministry of the Treasury] (2006). Kassenmäßige Steuereinnahmen nach Steuerarten [Fiscal revenues by tax type], available from: <http://www.bundesfinanzministerium.de/cln_06/nn_4158/DE/Steuern/ Steuerschaetzung_einnahmen/Steuereinnahmen/ 0601011a6002.html> [accessed 10 January 2008].

Calmus, T. W. (1981). Measuring the regressivity of gambling taxes. National Tax Journal, 34, 267-270.

Campbell, C. (1987). The Romantic Ethic and the Spirit of Modern Consumerism. Oxford, UK: B. Blackwell.

Clotfelter, C. T. (1979). Regressivity of state-operated numbers games. National Tax Journal, 32, 543-548.
Clotfelter, C. T. (2000). Do Lotteries Hurt the Poor? Well, Yes and No. A summary of testimony given to the house select committee on a state lottery. $<$ http://www.pubpol.duke.edu/news/newsletters/ dpn/summer00/lottery.html $>$ [accessed November 14, 2008].

Clotfelter, C. T. and Cook, P. J. (1987). Implicit taxation in lottery finance. National Tax Journal, 40, 533-546.

Clotfelter, C. T. and Cook, P. J. (1991). Selling Hope. State Lotteries in America. Cambridge, MA: Harvard University Press.

Cohen, L. R. (2001). The lure of the lottery. Wake Forest Law Review, 36, 705-745.

Cosgrave, J. and Klassen, T. R. (2001). Gambling against the state: the state and the legitimation of gambling. Current Sociology, 49, 1-15.

Deutsche Hauptstelle für Suchtfragen e.V. [German Central Office for Addiction Issues] (Eds.) (2006). Jahrbuch Sucht 2006 [Addiction Yearbook 2006]. Geesthacht: Neuland.

Deutschmann, M., Faulbaum, F. and Kleudgen, M. (2003). Computer Assisted Pretesting of Telephone Interview Questionnaires (CAPTIQ). Proceedings of the American Statistical Association, Survey Research Section. New York: ASA.

Devereux, Jr, E. C. (1980)[1949]. Gambling and the Social Structure. A Sociological Study of Lotteries and Horse Racing in Contemporary America. New York: Arno Press.

Downes, D. M. et al. (1976). Gambling, Work and Leisure. London: Routledge and Kegan Paul Ltd.

Findlay, J. M. (1986). People of Chance: Gambling in American Society From Jamestown to Las Vegas. New York: Oxford University Press.

Frey, J. H. (1984). Gambling: a sociological review. Annals of the American Academy of Political and Social Science, 474, 107-121.

Friedman, M. and Savage, L. J. (1948). The utility analysis of choices involving risk. The Journal of Political Economy, 56, 279-304.

Gabler, S. and Häder, S. (1997). Überlegungen zu einem Stichprobendesign für Telefonumfragen in Deutschland [Advisements on a sampling design for telephone surveys]. ZUMA-Nachrichten [ZUMA-News], 41, 7-18.

Garvía, R. (2007a). Syndication, institutionalization, and lottery play. American Journal of Sociology, 113, 603-652.

Garvía, R. (2007b). Socioeconomic Determinants of Syndicate Play, Manuscript, Carlos III University of Madrid.

Groves, R. M. et al. (2002). Survey Nonresponse. New York: John Wiley and Sons, INC. 
Guillén, M. F., Garvía, R., and Santana, A. (2008). Embedded Play. Economic and Social Motives for Sharing Lottery Tickets, Manuscript, Carlos III University of Madrid.

Gujarati, D. N. (2003). Basic Econometrics. Boston: McGraw Hill.

Hagenaars, A. J. M., de Vos, K., and Zaidi, M. A. (1994). Poverty Statistics in the Late 1980s: Research Based on Micro-data. Luxembourg: Office for Official Publications of the European Communities.

Hansen, A. (1995). The tax incidence of the Colorado state lottery instant game. Public Finance Quarterly, 23, 385-398.

Hansen, A., Miyazaki, A. D. and Sprott, D. E. (2000). The tax incidence of lotteries: evidence from five states. Journal of Consumer Affairs, 34, 182-203.

Heavey, J. F. (1978). The incidence of state lottery taxes. Public Finance Quarterly, 6, 415-426.

Heckman, J. J. (1979). Sample selection bias as a specification error. Econometrica, 47, 153-161.

Husz, O. (2002). Private dreams and public expectations. Lotteries and dilemmas of progress and social welfare in early 20th-century Sweden. Journal of Consumer Culture, 2, 53-79.

Jackson, R. (1994). Demand for lottery products in Massachusetts. Journal of Consumer Affairs, 28, 313-325.

Kahneman, D. and Tversky, A. (1979). Prospect theory-analysis of decision under risk. Econometrica, 47, 263-291.

Karcher, A. J. (1989). Lotteries. New Brunswick: Transaction Publishers.

Karcher, A. J. (1992). State lotteries. Society, 29, 51-56.

King, K. M. (1985). Gambling: three forms and three explanations. Sociological Focus, 18, 235-248.

Kitchen, H. and Powells, S. (1991). Lottery expenditures in Canada: a regional analysis of determinants and incidence. Applied Economics Letters, 23, $1845-1852$.

Koza, J. R. (1982). The myth of the poor buying lottery tickets. Public Gaming, 10, 31-50.

Liebig, S. and Mau, S. (2005). Wann ist ein Steuersystem gerecht? Einstellungen zu allgemeinen Prinzipien der Besteuerung und zur Gerechtigkeit der eigenen Steuerlast [When is a tax system just? Attitudes towards general principles of taxation and the justice of tax burdens]. Zeitschrift für Soziologie [Journal of Sociology], 34, 468-491.

Livernois, J. R. (1987). The redistributive effects of lotteries-evidence from Canada. Public Finance Quarterly, 15, 339-351.
Long, J. S. (1997). Regression Models for Categorical and Limited Dependent Variables. Thousand Oaks: Sage Publications.

McCaffery, E. J. (1994). Why people play lotteries and why it matters. Wisconsin Law Review, 71, $71-122$.

McConkey, C. W. and Warren, W. E. (1987). Psychographic and demographic profiles of state lottery ticket purchasers. Journal of Consumer Affairs, 21, 314-327.

Meyer, G. (2006). Glücksspiel-Zahlen und Fakten (Gambling facts and figures). In Deutsche Hauptstelle für Suchtfragen e.V. [German Central Office for Addiction Issues] (Eds.), Jahrbuch Sucht 2006 [Addiction Yearbook 2006]. Geesthacht: Neuland, pp. 114-128.

Mikesell, J. L. (1989). A note on the changing incidence of state lottery finance. Social Science Quarterly, 70, 513-521.

Miyazaki, A. D., Hansen, A. and Sprott, D. E. (1998). A longitudinal analysis of income-based tax regressivity of state-sponsored lotteries. Journal of Public Policy \& Marketing, 17, 161-172.

Murphy, L. and Nagel, T. (2002). The Myth of Ownership: Taxes and Justice. New York: Oxford University Press.

Nibert, D. (2000). Hitting the Jackpot. New York: Monthly Review Press.

Nibert, D. (2006). State lotteries and the legitimation of inequality. In Cosgrave, J. F. (Ed.), The Sociology of Risk and Gambling Reader. New York: Routledge, pp. 319-338.

Oster, E. (2004). Are all lotteries regressive? Evidence from the powerball. National Tax Journal, 57, 179-187.

Price, D. I. and Novak, E. S. (1999). The tax incidence of three texas lottery games: regressivity, race, and education. National Tax Journal, 52, 741-751.

Reith, G. (1999). The Age of Chance. Gambling in Western Culture. London: Routledge.

Rogers, P. (1998). The cognitive psychology of lottery gamblings. A theoretical review. Journal of Gambling Studies, 14, 111-134.

Rogers, P. and Webley, P. (2001). "It could be us!": cognitive and social psychological factors in UK national lottery play. Applied Psychology, 50, 181-199.

Sawkins, J. W. and Dickie, V. A. (2002). National lottery participation and expenditure: preliminary results using a two stage modelling approach. Applied Economics Letters, 9, 769-773.

Scott, F. and Garen, J. (1994). Probability of purchase, amount of purchase, and the demographic 
incidence of the lottery tax. Journal of Public Economics, 54, 121-143.

Smith, R. W., Preston, F. W. and Humphries, H. L. (1976). Alienation from work. A study of casino card dealers. In Eadington, W. R. (Ed.), Gambling and Society. Springfield, Ill.: Thomas, pp. 229-246.

Spiro, M. H. (1974). Tax incidence of Pennsylvania lottery. National Tax Journal, 27, 57-61.

Stranahan, H. A. and Borg, M. O. (1998). Separating the decisions of lottery expenditures and participation: a truncated Tobit approach. Public Finance Review, 26, 99-117.

Suits, D. B. (1977a). Gambling taxes: regressivity and revenue potential. National Tax Journal, 30, 19-35.

Suits, D. B. (1977b). Measurement of tax progressivity. American Economic Review, 67, 747-752.

Tec, N. (1964). Gambling in Sweden. Totowa: Bedminster Press.

Tobin, J. (1958). Estimation of relationships for limited dependent variables. Econometrica, 26, 24-36.

Tolkemitt, T. (2002). Die deutsche Glücksspielindustrie. Eine wirtschaftswissenschaftliche Analyse mit rechtspolitischen Schlussfolgerungen [The German gambling market. An economic analysis with arguments for legal policies]. Frankfurt/M.: Lang.

Vaillancourt, F. and Grignon, J. (1988). Canadian lotteries as taxes: revenues and incidence.
Canadian Tax Journal (Revue Fiscale Canadienne), 36, 369-388.

Vasche, J. D. (1985). Are taxes on lotteries too high. Journal of Policy Analysis and Management, 4, 269-271.

Winship, C. and Mare, R. D. (1992). Models for sample selection bias. Annual Review of Sociology, 18, 327-350.

Wood, R. T. and Williams, R. J. (2007). "How Much Money Do You Spend on Gambling?" The comparative validity of question wordings used to assess gambling expenditure. International Journal of Social Research Methodology, 10, 63-77.

\section{Authors' Addresses}

Jens Beckert (to whom correspondence should be addressed), Max Planck Institute for the Study of Societies, Paulstr. 3, 50676 Cologne, Germany. Email: beckert@mpifg.de; lutter@mpifg.de

Mark Lutter, Max Planck Institute for the Study of Societies, Paulstr. 3, 50676 Cologne, Germany. Email: lutter@mpifg.de

Manuscript received: January 2008 